\title{
Afetos no engajamento político das Marchas das Vadias no Brasil (2011-2017)
}

\author{
Morgani Guzzo' (iD) 0000-0002-5200-7293 \\ Cristina Scheibe Wolff' (iD) 0000-0002-7315-1112 \\ 'Universidade Federal de Santa Catarina, Florianópolis, SC, Brasil. 88040-900- \\ hst@contato.ufsc.br
}

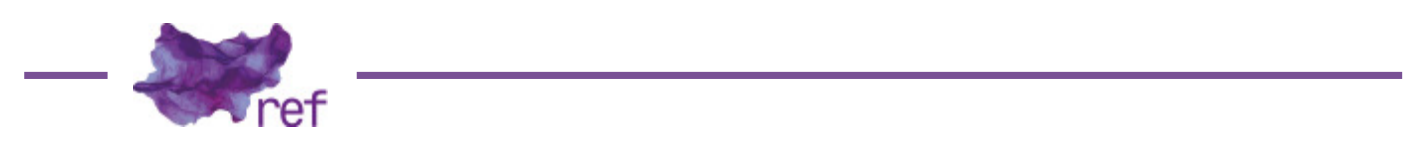

Resumo: Os afetos que atravessam os corpos tanto são moldados pelas estruturas e práticas políticas e sociais quanto são capazes de moldá-las (Sara AHMED, 2015). Emoções como a dor e a indignação, sentidas por sujeitas do feminismo diante da opressão e da desigualdade, podem tanto transformar quanto serem transformadas em espaços coletivos de luta, fazendo surgir a esperança, o pertencimento e a força no contato entre corpos e subjetividades. Por meio da análise de entrevistas feitas com organizadoras das Marchas das Vadias de cinco capitais brasileiras, neste artigo visamos à análise do papel das emoções e dos afetos no engajamento das ativistas com o feminismo das MdV, consideradas mobilizações que recolocaram as reivindicações feministas nas ruas, a partir da segunda década do século XXI.

Palavras-chave: feminismo; afetos; política; manifestações; Marcha das Vadias.

Affects in the Political Engagement in the Brazilian Marchas das Vadias (2011-2017)

Abstract: The affects that cross bodies are both shaped by and capable of shaping political and social structures and practices (Sara AHMED, 2015). Emotions such as pain and indignation, felt by feminist subjects in the face of oppression and inequality, can both transform and be transformed into collective spaces of struggle, giving rise to hope, belonging and strength in the contact between bodies and subjectivities. Through the analysis of interviews with organizers of Marchas das Vadias in five Brazilian capitals, this article aims to analyze the role of emotions and affects in the engagement of activists with the feminism of the $M d V$, considered mobilizations that put the feminist claims back in the streets from the second decade of the 21st century.

Keywords: feminism; affects; politics; manifestations; Marcha das Vadias.

\section{O lugar dos afetos}

Pensar os afetos, a dimensão do sensível e a forma como nosso corpo reage a determinadas falas, imagens e situações, mesmo quando difícil de colocar em palavras, são aspectos que, por muito tempo, não foram considerados relevantes nas análises das ações humanas e, como parte delas, da política. No entanto, Baruch Espinosa, no século XVII, na margem do que se tornaria a hegemonia científica e social no ocidente a partir de então, já argumentava ser impossível separar mente e alma, razão e emoção, pois ambos os aspectos compõem o que é humano e são igualmente importantes para a leitura e interpretação dos fenômenos (Chantal JAQUET, 2011).

Mais recentemente, principalmente a partir da segunda década do século XX, com a história das mentalidades e das sensibilidades, perspectivas que aproximam o que é considerado racional e o que é tido como afetivo/emocional vêm sendo desenvolvidas por várias/os autoras/es em diversas áreas do conhecimento. Alguns/mas deles/as têm chamado este movimento nas 
ciências humanas e sociais de "Affective Turn", uma "virada" que considera a perspectiva dos afetos como uma nova ontologia.

Segundo Gregory J. Seigworth e Melissa Gregg (2010), afeto é o nome que se dá às forças vitais que insistem para além das emoções e que podem servir para nos incitar ao movimento, ao pensamento e à extensão, podem nos suspender ou podem, ainda, nos deixar subjugadas/os. "[...] é uma prova persistente de que um corpo nunca é menos do que uma imersão contínua em e entre as obstinações e ritmos do mundo, suas recusas tanto quanto seus convites"' (SEIGWORTH; GREGG, 2010, p. 5 [tradução nossa]).

A compreensão dos afetos como algo que atravessa os corpos e que não passa, necessariamente, por algo consciente, possível de enunciar, ao mesmo tempo em que é compartilhada por alguns/mas autores/as, é alvo de críticas. Para Clare Hemmings (2005), é preciso ter cuidado para não entender os afetos como algo fora do significado social, pois a relevância dos afetos para a teoria cultural está exatamente em compreendê-los como algo que não é autônomo.

Assim, o exercício de pensar emoções e afetos como algo que atravessa os corpos e os move, de acordo com o contexto social e as experiências vividas pelas/os sujeitas/os afetados, tem sido desenvolvido por teóricas como Sara Ahmed $(2015$; 2018$)$ que, mais que compreender o que são afetos ou emoções, tem proposto pensar como as emoções circulam, como se fixam, como se movem, o que fazem e de que forma determinam práticas.

Ao refletir sobre as mobilizações feministas, o lema "o privado é político" (Joana Maria PEDRO, 2000; 2006; 2008), além de evidenciar o aspecto público da luta das mulheres (por direitos civis, contra os vários tipos de violência, a maternidade compulsória, a divisão sexual do trabalho, entre outras), também possibilitou ampliar as perspectivas teóricas das análises históricas e sociais, demonstrando as relações entre a dimensão subjetiva e a política e construindo alternativas às perspectivas dicotômicas, tanto da ciência quanto das políticas públicas, como aquelas relacionadas às violências de gênero, por exemplo.

Com base em entrevistas realizadas durante trabalho de campo da pesquisa de Doutorado (Morgani GUZZO, 2019) ${ }^{2}$ com organizadoras das Marchas das Vadias de cinco capitais brasileiras, ${ }^{3}$ buscamos, neste artigo, refletir sobre a relação entre os afetos e a mobilização política feminista. Dividimos esta abordagem em três âmbitos, relacionados aos afetos enunciados pelas organizadoras como razões de seu engajamento: a identificação com a pauta, os sentidos suscitados durante as manifestações e a afinidade com a forma de organização.

A análise a partir dos afetos permite ampliar o escopo das questões basilares nos estudos dos movimentos sociais, como: quem são as protagonistas, como se organizam, com quais objetivos e estratégias e que resultados alcançam. A menção das interlocutoras às emoções e afetos envolvidos na sua atuação nas Marchas significa que, a partir dos processos de significação, estes afetos foram compreendidos e considerados relevantes para a sua mobilização política. Nosso enfoque objetiva compreender de que maneira os afetos e as emoções enunciadas podem ser lidas como o que as moveu, as fez ir para a rua e as motivou a participar de grupos organizados de luta feminista. A partir de suas experiências, é possível pensar o quanto é afetiva uma atuação política e o quanto há de política em relações afetivas.

\section{As dores}

A Marcha das Vadias ${ }^{4}$ - que surge no Canadá, em 2011, com o nome de SlutWalk -, colocou em foco os discursos institucionais de culpabilização das vítimas pelas violências sofridas, denunciando-os como parte da cultura do estupro propagada em sociedades patriarcais e misóginas. ${ }^{5}$ Devido ao nome e à forma como as manifestantes se vestiam durante o protesto, a manifestação ganhou destaque nos meios de comunicação e chegou a ser organizada em mais de duzentas cidades em todo o mundo.

No Brasil, as Marchas das Vadias foram realizadas em várias cidades entre 2011 e 2017,6 com características muito distintas entre si, considerando o contexto de desigualdade social fundado em uma estrutura de opressão interseccional que mescla classe, raça, gênero, sexualidades, entre outros, desde o período colonial. Dessa forma, as pautas levantadas pelas Marchas das Vadias brasileiras vinculam-se não só à culpabilização das vítimas de violência, mas às múltiplas formas de violência relacionadas ao preconceito de gênero e de raça vivenciadas pelas mulheres, cis ou trans, em diferentes espaços e camadas sociais. Estas características permitem perceber que as mobilizações "das vadias" formaram parte de um processo de pluralização dos feminismos brasileiros, especialmente entre jovens, na segunda década do século XXI.

Além do nome polêmico, as Marchas chamaram atenção por sua estética considerada "provocante", composta por manifestantes seminuas ou usando shorts ou saias curtas, com frases pintadas nos corpos; e pela exposição das reivindicações por meio de performances espontâneas, cartazes, jograis, cantos e gritos de desordem entoados durante a caminhada. Com essa estética, as manifestantes objetivavam questionar o discurso que relacionava a violência à forma como 
elas se vestem e ao local e horário em que circulam nas ruas. Ao se contrapor à frase misógina dita pelo policial canadense, as "vadias" brasileiras diziam: "se ser livre é ser vadia, então somos todas vadias".

Para muitas das pessoas que organizaram as Marchas das Vadias brasileiras, o interesse em participar da manifestação esteve relacionado à identificação com a pauta: a luta contra a ordem do sensível (Jacques RANCIÈRE, 2005), que determina os sujeitos e a forma de comportamento que devem ter para serem visíveis e audíveis na sociedade, e que faz com que determinados corpos e formas de expressão sejam considerados abjetos, invisíveis e merecedores de violência, como no caso do discurso que justifica que corpos femininos sejam violentados dependendo da roupa que os cobre, da hora e do local em que circulam.

Para Luana, uma das organizadoras da MdV de Salvador, a identificação com a pauta a motivou a participar da Marcha, principalmente por já ter sido vítima da violência contra a qual a manifestação se posiciona.

[...] principalmente a ideia de que não há justificativa para um estupro. Não há justificativa de "sua roupa é curta, você é puta, você é vadia, você estava andando à noite sozinha, você estava num lugar escuro..." [...] há sempre desculpas e mais desculpas do porquê a mulher foi estuprada, mas não há um questionamento do estuprador. Então, nesse sentido que eu me identifiquei com a Marcha das Vadias, por sentir, também, muito na pele de ser tratada de forma diferente pela maneira que você se veste, pela maneira que você se comporta, pela sua sexualidade, e isso não tem uma justificativa, não adianta tentar construir isso enquanto um argumento que justifique um ato de violência contra a mulher, isso não faz o menor sentido (Luana, MaV de Salvador, 2017).

Os discursos naturalizados que tentam justificar a violência contra as mulheres, apontados por Luana, correspondem à ordem policial (RANCIÈRE, 1996), que funciona como dispositivo de opressão dos corpos e subjetividades. A forma como a linguagem mobiliza a razão para a interdição dos espaços de circulação e do comportamento das mulheres faz a violência operar como sanção à desobediência dessa ordem. Esses discursos, produtos de um regime de inteligibilidade processado automaticamente, foram construídos historicamente, ligados a valores morais e religiosos, e funcionam, segundo Julia Antivilo Peña (2015), como dispositivo de controle dos corpos das mulheres na América Latina, desde o processo colonial.

Para Peña (2015), embora a colonização tenha construído, além da divisão por gênero, a divisão racial entre os corpos femininos (corpos brancos ligados à castidade, corpos indígenas e negros ligados à impureza e ao pecado), todos deveriam estar sob o controle. O "olhar cristão" foi responsável, também na mentalidade das mulheres na longa duração, por "[...] la estrecha relación con sus cuerpos; cuerpos que se han erigido mediante un riguroso control social desplegado a través de la censura y de la autocensura, instalando la lógica que niega la propiedad del cuerpo propio" (PEÑA, 2015, p. 36).

O controle e a negação da propriedade do próprio corpo pelas mulheres compõem o discurso contra o qual se originou a Marcha das Vadias, que diz que os corpos que não se adequam ao regime de inteligibilidade imposto pelo cisheteropatriarcado ${ }^{7}$ estão sujeitos à violência. Além deste aspecto, Luana menciona a violência "sentida na pele" quando recebe tratamento diferenciado dependendo como se veste ou se expressa, evidenciando, assim, outro aspecto sensível: a forma como o corpo e a subjetividade são afetados pelas estruturas sociais. Por serem menos visíveis que as violências físicas e menos denunciadas aos serviços de saúde e segurança, as violências psicológica, moral e simbólica (sentir-se julgada e violentada), embora muitas vezes indissociáveis de outros tipos de violência, são frequentemente desconsideradas e poucas vezes problematizadas na esfera das políticas públicas.

\footnotetext{
1 "[...] is persistent proof of a body's never less than ongoing immersion in and among the world's obstinacies and rhythms, its refusals as much as its invitations" (SEIGWORTH; GREGG, 2010, p. 5).

${ }^{2} \mathrm{Na}$ pesquisa analisou-se as formas de organização, as estratégias, pautas e os diferentes corpos e campos construídos pelas Marchas das Vadias no Brasil.

${ }^{3}$ As entrevistas foram realizadas com organizadoras das Marchas que continuavam sendo organizadas no período de 2015 a 2017 . A partir de contatos feitos pelas redes sociais e, dependendo das respostas recebidas, as entrevistas eram agendadas. Algumas ocorreram durante os dias em que a pesquisadora esteve acompanhando a organização das Marchas (como no caso de Fortaleza, Salvador e Florianópolis) e outras foram realizadas em outros momentos de encontro com as organizadoras (como em Curitiba) ou pelo WhatsApp (caso de algumas da Marcha do Rio de Janeiro e, também, de Fortaleza).

${ }^{4} \mathrm{O}$ nome da Marcha também será abreviado como MaV ao longo do texto.

${ }^{5} \mathrm{~A}$ manifestação ocorreu após um policial dizer às estudantes, em uma palestra na Universidade de York, em Toronto, que elas deveriam evitar "se vestir como vadias" se não quisessem ser estupradas.

6 Embora este seja o recorte da pesquisa, em algumas cidades brasileiras, como Recife, as Marchas das Vadias continuam acontecendo.

7 O termo "cisheteropatriarcado" refere-se à junção de algumas das estruturas normativas e sistemas de opressão presentes em nossa sociedade, como a heterossexualidade compulsória, a cisnormatividade e o patriarcado. A categoria vem sendo utilizada por teóricas e ativistas feministas, especialmente lésbicas e trans e, também, foi mencionada (com variações) pelas interlocutoras da pesquisa.
} 
Assim como Luana, Regina, da MdV de Fortaleza, conta que a sua aproximação com a MdV se deu, também, por ter sofrido com as violências.

[...] o que me motiva a estar em algum lugar que é feminista e que construa alguma luta feminista são as dores que eu já vivi ao longo da vida. Pra mim, fez muito sentido, [...] eu sofri muito porque eu acho que com dez, onze anos, começaram os primeiros assédios na rua, pesados mesmo [...] e eu muito novinha pra lidar com isso, chegava em casa chorando diversas vezes. Eu lembro que aqui no [bairro] Benfica eu passei quase um ano sendo perseguida pelo mesmo cara (Regina, MaV de Fortaleza, 2017).

O sentimento de impotência sentido por Regina diante do assédio vivido desde a adolescência demonstra a insuficiência da legislação e das instituições para garantir a sensação de segurança das mulheres. ${ }^{8}$ Além disso, a legislação sobre o assédio não dá conta dos agravantes desse tipo de violência, como o constrangimento e outros impactos psicológicos, como a ansiedade gerada pelo medo.

De acordo com Susana Velásquez (2003), o medo de ser assediada ou violentada é algo que atinge, principalmente, as mulheres, pois foi sendo construído socialmente por causa dos estereótipos de gênero e da hierarquia de poder, que colocam as mulheres em posição inferior com relação aos homens e, portanto, de maior vulnerabilidade. Assim, para a pesquisadora, a violência é a estratégia fundamental para manter esse esquema de autoridade. "Es así como las mujeres deben convivir con la violencia o con el temor a que 'algo les suceda', y al mismo tiempo deben evitarla ideando variadas conductas de resguardo y defensa" (NELÁSQUEZ, 2003, p. 44). A sensação de perigo e de medo, segundo Velásquez (2003), tem criado uma realidade codificada para as mulheres, que pode propiciar, em cada uma delas, que se sinta uma vítima provável. "La consecuencia será una percepción difusa de vulnerabilidad e inseguridad personal que puede promover - en algunas mujeres - la restricción de movimientos, de horarios y de actividades, hasta la reclusión y el aislamiento" (VELÁSQUEZ, 2003, p. 43). Para Velásquez (2003), além da força física, outros tipos de violência, como a violência emocional, invisível, simbólica e econômica, exercem imposição social por pressão psicológica, cujos efeitos produzem tanto ou mais danos que a ação física (VELÁSQUEZ, 2003). Não obstante, para ela, todo ataque ao corpo é um ataque à identidade e à subjetividade.

Embora o medo e a dor pareçam emoções compartilhadas entre mulheres, devido aos inúmeros tipos de violência aos quais estão sujeitas, a possibilidade de estar em grupos feministas permite transformar a impotência em potência. Segundo Regina, o processo de ressignificar suas dores a motivou a estar em contato com pessoas que passam pelo mesmo tipo de opressão e lutam contra isso. Os espaços feministas têm historicamente proposto pensar como as opressões vividas de maneira individual e privada podem ser entendidas como resultado de uma estrutura.

De acordo com Ahmed (2015), o reconhecimento da dor, da discriminação e das violências contra as mulheres como algo estrutural e não individual tem sido fundamental para a política feminista, não só para a formação de sujeitos feministas, mas também de coletivos que têm se mobilizado em torno da demanda política e ética por reparação. No entanto, embora haja uma profunda relação entre a dor e o feminismo, Ahmed (2015) argumenta que, para evitar tomá-la como "objeto fetiche", é preciso "[...] aprender a recordar cómo los sujetos corporizados llegan a estar heridos, lo que requiere que aprendamos a leer ese dolor [...] hacer el trabajo de traducción" (AHMED, 2015, p. 263 [grifo da autora]). Além disso,

[...] no se trata solo de que el dolor nos impulse a movernos hacia el feminismo, o impulse al feminismo como un movimiento de transformación social y política. La respuesta al dolor, como llamado a la acción, también necesita indignación: la interpretación de que este dolor está mal, que es una atrocidad, y que se debe hacer algo al respecto (AHMED, 2015, p. 264).

Para algumas das organizadoras das Marchas das Vadias, sentir na pele as opressões, processar as dores, dar nomes a elas e indignar-se foi o que as levou a participar das Marchas das Vadias, em um processo de contato com outras subjetividades que transformou afetos de impotência em potência, relacionada à sensação de que "algo deve ser feito" e que esse algo é a luta feminista.

\section{O assombro}

As manifestações da Marcha das Vadias podem ser compreendidas como espaços e momentos em que os sentidos ficam "à flor da pele", pois os corpos, tanto de quem participa das

\footnotetext{
${ }^{8}$ Pela legislação brasileira, o assédio sexual é passível de punição pelo artigo 216 do Código Penal, que estabelece: "Constranger alguém com intuito de levar vantagem ou favorecimento sexual, prevalecendo-se o agente de sua forma de superior hierárquico, ou ascendência inerentes a exercício de emprego, cargo ou função". Nesta mesma legislação, - artigo 233 enquadra como Ato Obsceno quando alguém pratica uma ação de cunho sexual (como exibir os genitais) em local público, a fim de constranger ou ameaçar alguém. Outra tipificação é o assédio verbal, caracterizado pelo artigo 61, da Lei de Contraversões Penais $n^{\circ}$. 3.688/1941, que estabelece crime de baixo potencial ofensivo quando alguém diz coisas desagradáveis ou invasivas ou faz ameaças a outra pessoa. Neste caso, entraria a situação das "cantadas" dos homens direcionados às mulheres e que as fazem se sentirem invadidas, ameaçadas ou encabuladas.
} 
Marchas quanto de quem as observa de fora, são afetados por uma profusão de contatos corporais, imagens e sons. A maneira como os corpos são afetados, no entanto, depende de diversos fatores, como as experiências passadas, os locais e formas de socialização, os valores que permeiam sua decodificação e interpretação do mundo, entre outros.

A proposta estética provocativa das MdV é considerada, pelas organizadoras, potencializadora da mobilização, tanto pelos sentidos positivos (de força, união entre as manifestantes), quanto pelos considerados negativos (as reações de repulsa e desaprovação de quem observa a Marcha ou de grupos críticos a ela, inclusive feministas). Seja como resultado de uma estratégia para gerar impacto, ou como reação não prevista, a provocação da ordem do sensível (RANCIĖRE, 2005) pelas MdV marcou o imaginário social brasileiro a respeito das feministas.

No Brasil, a denúncia da culpabilização das vítimas e da cultura do estupro é articulada com a reivindicação pela autonomia dos corpos. A frase mais conhecida da manifestação, "meu corpo, minhas regras", demonstra este segundo aspecto e atualiza um dos slogans mais famosos do feminismo desde 1970. A reivindicação da autonomia se evidencia pelas performances "provocativas": com roupas curtas, seios à mostra ou fantasiadas das mais diferentes formas, as/os manifestantes ampliam o repertório da expressividade de gênero durante o protesto. As frases escritas sobre a pele também fazem do corpo a própria bandeira, provocando olhares curiosos de quem passa.

A reivindicação do "direito ao próprio corpo" diz respeito não só à luta para que se possa andar nas ruas em segurança, mas, também, ao direito de amar, sentir afetos diversos e viver sua identidade de gênero e sexualidade de maneira livre na sociedade. O direito à sexualidade e à afetividade não heteronormativas ganha notoriedade, principalmente, nas Marchas construídas por pessoas que se identificam como bissexuais e lésbicas. Como forma de demonstrar que todos os afetos e tipos de amor são possíveis e aceitos, as "vadias" cantam: "eu amo homem, amo mulher, tenho direito de amar quem eu quiser!", "se o mundo, se o mundo fosse cheio de sapatão, seria a revolução, revolução das sapatão". Além disso, em momentos de pausa na Marcha, geralmente em frente a igrejas católicas e evangélicas, algumas manifestantes fazem "beijaços", isto é, beijam-se na boca, enfrentando a moral que coloca os afetos não heterossexuais no lugar do desvio, da doença, da perversão.

As MdV no Brasil também são marcadas pela presença, no espaço público, de pessoas que fogem do modelo de feminilidade ou de masculinidade cisgênero. No Rio de Janeiro, por exemplo, mulheres trans, travestis e prostitutas tomam a frente da Marcha, não só se tornando o símbolo da manifestação na cidade e dando visibilidade para as pessoas "travestigeneres", mas também agindo como "escudo" no caso de serem denunciadas à Polícia por "atentado ao pudor". Pessoas trans e travestis também compõem a Marcha das Vadias de Fortaleza, performam "personagens" durante a Marcha das Vadias de Salvador e de Curitiba; e, algumas, se "descobrem" e iniciam seus processos de transição de gênero durante os anos de realização da Marcha das Vadias de Florianópolis (2011-2015). ${ }^{10}$

A presença desses corpos no espaço público tensiona a ordem do sensível. Ao provocar o deslocamento dos espaços em que prostitutas e pessoas trans são costumeiramente vistas nas cidades brasileiras, tirando-as da margem e colocando-as em evidência, as MdV afetam os sentidos e desestabilizam, também, os padrões de inteligibilidade sobre os corpos e o espaço público. Já as mulheres cis provocam deslocamentos do padrão de feminilidade e da estética "desejável" para o corpo "feminino", vendido e consumido a partir das propagandas, do carnaval, dos programas de televisão, das capas de revista, da pornografia e da imagem do "anjo do lar" doméstico. Corpos não brancos, gordos, diversos, que fogem "às medidas" e à noção de feminilidade reivindicam o direito ao espaço público e o seu lugar como sujeitas desejantes e de desejo.

Os sentidos também são provocados pelas performances realizadas durante as manifestações. Sejam programadas ou espontâneas, as performances acontecem nos momentos de paradas durante o trajeto da Marcha, em locais estrategicamente escolhidos, como em frente a igrejas. Luana descreve uma que foi realizada na primeira MdV de Salvador.

[...] as mulheres entravam com roupas sensuais e bem maquiadas, e aí conforme o texto ia declamando, que era um texto que desconstruía a mulher pelos objetos de maquiagem, de seio, de sapato, as meninas iam borrando, assim, as maquiagens, e se apertando... pra causar incômodo mesmo nas pessoas, até porque era o primeiro ano, então, era no sentido de causar um choque mesmo [...] E rolou (Luana, MdV de Salvador, 2017).

As performances, a união entre arte e política objetivam, também, afetar as pessoas que observam as Marchas. Para Luana, se aquelas que não concordam com a manifestação se sentirem atingidas, sentirem algum tipo de incômodo, já é um resultado positivo da Marcha.

\footnotetext{
9 "Travestigeneres" foi o nome cunhado pela ativista transfeminista Indianara Siqueira para se referir às pessoas travestis, transexuais e transgêneras usando um só termo.

${ }^{10}$ Para uma das organizadoras da MdV de Florianópolis, as afinidades, amizades e o espaço de liberdade criado pela Marcha das Vadias facilitaram seu processo de se "descobrir" e passar a viver como mulher trans.
} 
A provocação como estratégia, no entanto, não é uma inovação da MdV, mas vem sendo usada na arte e nas ações políticas feministas desde os anos 1960-70, em experimentações decoloniais (PEÑA, 2015), em coletivos como o Mujeres Creando, da Bolívia, entre inúmeros outros exemplos. Em performances ousadas e bem humoradas nos centros das cidades, cria-se o impacto por meio do escândalo que provocam (PEDRO, 2008).

O impacto é afeto. No caso das MdV brasileiras, a afetação que poderia acontecer de qualquer forma, na medida em que muitas marchas fecham as ruas e impedem carros e pedestres de passarem normalmente, ocorre, também, por meio do incômodo gerado pelas performances. Tendo em conta o padrão estético de inteligibilidade compartilhado, que é histórico e social, as performances demonstram como os afetos são, também, sociais e coletivos, pois podem ser estimulados, como quando determinadas ações que tensionam a ordem geram reações de espanto (ou "assombro"), choque e reprovação nos observadores.

[...] eu acho que em diversos níveis a gente vai tocando as pessoas. Algumas se ofendem [...], porque não entendem nem que aquilo seja possível, que seja permitido. "Como vocês estão aqui? Vão pra casa! Vão se vestir!" Algumas discussões religiosas também, de que "ah, mulher não é pra isso". Então, esse enfrentamento com o público a gente consegue perceber o quanto que mexe com as pessoas, assim como mexe com a gente (Luana, MaV de Salvador, 2017).

Os xingamentos e gritos de reprovação ouvidos pelas manifestantes durante as Marchas demonstram que qualquer forma de expressão do corpo das mulheres, que não seja aquela imposta pelo padrão normativo, é rechaçada. O tensionamento da ordem do sensível, o deslocamento daquilo que é esperado, portanto, gera reações relacionadas muito mais à forma de dizer do que ao que é dito. Isto é, defender que ninguém merece ser estuprada, independente da roupa, não está errado; o errado é fazer isso se vestindo "como vadia". Defender que as decisões sobre si e sobre seu corpo são do próprio sujeito não está errado, o errado é fazer isso usando, efetivamente, seu corpo, colocando no espaço público seus afetos e escancarando sua subjetividade.

No entanto, não só as pessoas que observam a Marcha são impactadas pelo protesto; as próprias manifestantes sentem-se "mexidas". Sentir-se afetada pela Marcha das Vadias está relacionada, segundo Luana, às suas próprias experiências enquanto mulher na sociedade. Para Ahmed (2018), os discursos sobre a violência e as experiências vividas durante a construção social e subjetiva do sujeito "mulher" transformam nosso corpo, mudam a forma como vivemos no mundo e, também, a forma como interpretamos o que vivemos: quando percebemos o mundo como um perigo, nos tornamos mais cautelosas e mais tímidas para prevenir a violência, e nos movemos como se já esperássemos que ela fosse acontecer a qualquer momento. Segundo Ahmed (2018), isso torna as mulheres medrosas, ao mesmo tempo em que cerceia a sua liberdade.

O processo de amedrontamento e reconhecimento de sua expressividade diante da ameaça de violência foi, no caso de Regina, da MdV de Fortaleza, transformado durante sua participação na Marcha, quando as violências vividas por ela se tornaram visíveis e públicas. Para Regina, estar na Marcha permitiu que ela se sentisse fortalecida para passar por lugares frequentados por homens que a conhecem e onde um deles sempre a assediava e ela nunca tinha tido coragem de reagir.

[...] eu lembro que me senti mais forte estando lá e gritando as palavras de desordem, e passando com a barriga de fora, que é uma coisa que eu não costumo usar no cotidiano - não costumava usar, porque agora eu estou ficando cada vez mais atrevida (risos) -, mas naquela época eu acho que eu sofria muito com os assédios, eu acho que eu não sabia reagir. Hoje eu nem ligo, respondo, reajo na hora, ou então deixo pra lá, às vezes eu acho graça, porque tem coisas engraçadas e que não me ferem. [...] em geral, eu acho que me senti muito fortalecida, é sempre fortalecedor pra mim construir algo coletivo, depois vem até uma certa ressaca, uma certa solidão, também, quando esses momentos acabam (Regina, MdV de Fortaleza, 2017).

A transformação do medo em força, vivida por Regina, demonstra uma das possibilidades que se abrem a partir de estar na rua, coletivamente. Ao contrário do processo de recolhimento e de limitação dos espaços de circulação de seu corpo, a MaV provocou em Regina o que Ahmed (2015) chama de "assombro", que permitiu que ela vivenciasse de forma diferente a caminhada pelo mesmo espaço, com mais "atrevimento", relacionado à liberdade para se expressar a despeito das violências sofridas. O assombro, isto é, a capacidade de ver e viver as coisas como se pela primeira vez, como se não fossem dadas, foi o que levou Ahmed (2015) ao feminismo, pois, segundo ela, esse afeto ajuda a dar-se conta de que o que dói e causa dor, o que sentimos que está mal, não é necessário e pode desfazer-se. "El asombro inyecta energía a la esperanza de transformación y a la voluntad para la acción política" (AHMED, 2015, p. 274).

Para Antônia, foi também o sentimento de assombro pelo "clima meio anárquico", as frases e gritos improvisados da MdV do Rio de Janeiro que a mobilizaram politicamente. 
[...] eu me lembro que naquele ano a Marcha [...] passou em frente à igreja, umas minas entraram, tava tendo missa, foi a maior confusão, e eu comecei a gritar lá na frente, uma igreja católica, eu comecei a gritar "Maria Madalena também era vadia" - porque ela era, nessa visão do que é uma vadia, uma mulher que é julgada pela sua sexualidade ou personalidade, e Jesus Cristo andou com ela, perdoou ela... E foi muito maneiro porque quando eu comecei a gritar isso todo mundo começou a gritar junto. Então, eu acho que, ali, a mosquinha mordeu (Antônia, MdV do Rio de Janeiro, 2017).

A possibilidade de, na sua primeira Marcha, puxar um grito e ver que as pessoas endossavam sua frase gerou em Antônia uma sensação de pertencimento e de união de forças: a voz (e pauta) de uma torna-se a voz/pauta de todas. Além disso, o "assombro", para ela, também teve relação com a "energia" do protesto.

[...] é uma coisa de ter energia muito alta, ter uma energia de diversão, ter uma energia de unidade, mas ter um lado muito subversivo mesmo, sabe? Nessa primeira Marcha que eu fui, que a gente parou em frente à igreja, e eu fiz esse grito da Maria Madalena, é uma coisa bemhumorada, não é uma coisa agressiva, [...] mas é subversivo, porque você tá falando pros caras que tão dentro da igreja, que se Jesus estivesse vivo aqui hoje ele ia estar do nosso lado e não do lado deles (Antônia, MaV Rio de Janeiro, 2017).

A junção entre irreverência, humor, "energia alta" e subversão provocou o engajamento em Antônia que, durante sua primeira Marcha, já se sentiu parte do grupo e identificou a dimensão coletiva da luta. Para muitas das organizadoras entrevistadas, foi durante o ato que elas passam a se perceber como pertencentes a um grupo que é oprimido por motivos específicos e que podem encontrar ali, na Marcha, o acolhimento e a potência transformadora de suas subjetividades.

Tornar coletiva a reação às sensações individuais é um trabalho feito pela política feminista, afinal, o pessoal é político. Como sugere Ahmed (2015), a pedagogia feminista pode ser pensada em termos de abertura afetiva para o mundo por meio do ato de assombrar-se não como algo privado, mas uma abertura para o que é possível por intermédio do trabalho conjunto, pois a capacidade de assombrar-se é algo para a qual se desperta (ou não) nos encontros, referente a como os corpos se veem afetados por outros corpos, transformando o que cada um pode fazer.

Assim, os corpos abertos, afetados, unidos nas manifestações da Marcha das Vadias estimulam os sentidos de maneira contingente e imprevisível. Os sentidos (visão, audição, tato) são provocados pela multiplicidade de bandeiras, de cores, de corpos; pelos olhares de simpatia e encorajamento; pelos gritos de desordem e pelos batuques em latas de tinta ou tambores; pelos abraços, beijos e toques efêmeros que ocorrem na Marcha. Nos encontros entre múltiplos corpos e bandeiras corporificadas, subjetividades entram em contato, provocando, também, os afetos, que diferem de pessoa para pessoa, já que não são propriedades de um corpo, mas são produzidas no contato, no encontro entre os corpos que, por sua vez, carregam diferentes experiências e histórias.

\section{Acolhimento e disputa}

O engajamento com as Marchas das Vadias também pode ocorrer pela afinidade política à proposta, compartilhada entre várias das MdV brasileiras, de construir um espaço político fora dos âmbitos institucionais, colocando as reivindicações na rua e organizando-se de forma horizontal, independentemente de partidos, sindicatos e do Estado.

Para algumas das organizadoras, este posicionamento, que elas chamam de "autônomo", está pautado em experiências anteriores de militância. Segundo Nathália, da MdV de Florianópolis, sua participação em grupos anarquistas na Espanha fez com que, ao retornar a Florianópolis, em 2013, ela buscasse um espaço com características políticas semelhantes para atuar. Ao saber que a Marcha das Vadias era organizada na cidade, ela participou de uma das manifestações e identificou nas frases, nos símbolos e nos cartazes menções ao feminismo anarquista. Assim, a partir de 2014, ela passou a participar de reunióes e percebeu que as demais organizadoras tinham um viés político parecido com o dela. Esta identificação gerou sentimento de acolhimento, que a levou a fazer parte da organização da Marcha a partir de então.

[...] acho que o que me levou para a Marcha foi isso, foi ter identificado nela, e realmente, quando eu chego na Marcha e vejo as organizadoras, quase todas elas se identificavam enquanto feministas anarquistas, e tinham pensamentos muito... Éramos diferentes, todas muito diferentes, mas a gente meio que olhava por um caminho político de luta muito parecido e eu me senti muito acolhida aí (Nathália, MdV de Florianópolis, 2017).

A afinidade política foi também o que motivou Ryane a fazer parte da organização da MdV de Florianópolis. No entanto, para ela, além da proximidade com a perspectiva anticapitalista, o posicionamento contrário à participação de partidos políticos e a luta contra o machismo articulada com outras pautas, o sentimento de acolhimento esteve relacionado ao fato de algumas das organizadoras se identificarem como lésbicas e bissexuais, o que demonstrava que o espaço não 
era heteronormativo (Berenice BENTO, 2008)." Somado a isso, a afinidade pelos motivos que as levavam para a rua e a forma como entendiam o feminismo, que não excluía homens ou pessoas trans, a fez se sentir à vontade com as demais pessoas, gerando afetos como admiração, amizade e, inclusive, relações afetivo-sexuais.

A identificação com a forma de organização também foi mencionada por Antônia, da MdV do Rio de Janeiro. Segundo ela, além do "clima anárquico" da manifestação, a metodologia da primeira reunião da qual participou a fez se sentir acolhida no grupo.

Fui sozinha, um pouco apreensiva, porque, né, chegar sozinha num lugar que você não conhece ninguém, e estava rolando a reunião, e eles estavam dividindo funções, quem ia fazer o quê. Naquele ano, em 2013, tinha comissões, uma comissão pra lidar com a imprensa, uma pra organizar, levantar dinheiro, organizar eventos, uma pra fazer o manifesto, aí eu, na minha primeira reunião, já entrei em algumas comissões, sem ter a menor ideia de onde eu estava me metendo, mas eu escolhi pelo que eu achei que eu ia saber fazer [...]. E essa coisa de ser horizontal, apesar de que eu não entendia dessas coisas na época, foi uma coisa que me atraiu imediatamente, eu não sou uma pessoa que gosta muito de hierarquia, e eu gosto de chegar fazer as coisas, de já meter a mão na massa mesmo, então isso funcionou (Antônia, MdV do Rio de Janeiro, 2017).

Para as organizadoras que, como Antônia, não tinham experiência de militância em espaços feministas ou autônomos, a forma aberta e horizontal da organização das MaV, que permitia que quem chegasse já colocasse "a mão na massa", gerava um sentimento de pertencimento imediato ao grupo.

As sensações de acolhimento e pertencimento nos espaços de construção das MdV podem estar relacionadas, também, ao que Ahmed (2015) chamou de esperança, que é o que nos leva a questionar o que se pode fazer, para onde se pode ir e que tipo de futuro se pode imaginar, pautada no desejo de não repetir o passado. Assim, a esperança, em uma proposta de construção política coletiva diferente dos modelos hegemônicos, é outro elemento de engajamento das organizadoras das MdV. Para Ahmed (2015), a esperança faz com que se possa desfrutar 0 envolvimento em diferentes formas de ativismo políico, o sentido de que "reunir-se" significa abrir o mundo, recuperar espaço por intermédio de "vínculos afetivos" (AHMED, 2015, p. 278).

A construção de um espaço de esperança feminista que "sai do conceitual" por se propor aberto à diversidade de pessoas interessadas é, para Luana, da MdV de Salvador, a maior potência da Marcha.

[...] é um feminismo que sai do conceitual, é um feminismo muito prático, então ele não exige de você que você seja nada. (risos). Somente exige que você se sinta identificada com essas violações e se você sofre essa violação você se sente acolhida aqui. Não é nem um tipo de segmento teórico ou conceitual que exclui isso ou aquilo ou que precisa de um modelo, qualquer mulher que você possa ser, independente de condição, de classe, de sexo, de gênero, de qualquer outra coisa, você passa por essas violações, você se identifica com esse tema, você é bem-vinda aqui. Não tem nenhum tipo de separação em relação a nenhum segmento de mulher. Aí eu acho que isso é um atrativo. Talvez seja um repelente pra quem é muito teórico, mas pra quem não tem teoria nenhuma, pra quem tá na rua sofrendo, pra quem tá no seu cotidiano sendo oprimida, eu acho que é uma abertura, porque não prevê que você tenha que ter algum conhecimento [...] sobre o feminismo pra estar ali, é apenas dizer que você não suporta mais ser violada. E como não suporta mais, você encontra uma pessoa pra lutar junto com você, mesmo que você não saiba dizer como, mesmo que você não saiba nomear [...] essa liberdade ajuda a agregar (Luana, MdV de Salvador, 2017).

Segundo Luana, a abertura, a "liberdade" por não estar pautada em determinada vertente do feminismo e a possibilidade de qualquer pessoa somar na luta ajuda a agregar pessoas, pois é uma prática política que leva em conta todas as formas de opressão, seja de classe, raça, gênero, orientação sexual etc. Assim, as MdV podem ser lidas como espaços pautados na esperança, cujo efeito é a abertura dos corpos diante da possibilidade de desejo ou felicidade ao contrário do medo, que fecha os corpos diante da possibilidade de perigo ou dor.

No entanto, como qualquer espaço político, os afetos não estão só ligados ao acolhimento. Para algumas das organizadoras das MdV, o conflito, as disputas e o dissenso não só são existentes, como são desejáveis. Para Regina, da MdV de Fortaleza, a possibilidade de ser sincera e honesta em expor as discordâncias é outro aspecto de potência da MaV.

Eu acho que a Marcha das Vadias que é construída aqui, eu me sinto mais à vontade pra discordar, eu acho que tem mais espaço, eu não me sinto convocada a ser sorora, por

\footnotetext{
${ }^{11}$ Ancorada nos aportes de Judith Butler, Berenice Bento (2008) entende que gênero é uma sofisticada tecnologia social heteronormativa, operacionalizada pelas instituições médicas, linguísticas, domésticas e escolares que produzem corpos-homens e corpos-mulheres. "Por heteronormatividade entende-se a capacidade da heterossexualidade apresentar-se como normal, a lei que regula e determina a impossibilidade de vida fora de seus marcos. É um lugar que designa a base de inteligibilidade cultural através da qual se naturaliza corpos/gênero/desejo e se definirá o modelo hegemônico de inteligibilidade de gênero" (BENTO, 2008, p. 51).
} 
exemplo, naquele sentido ali, que eu tenho que amar todo mundo. Óbvio que me sinto sempre convocada a ser solidária quando acho que a pessoa tá na luta comigo, é óbvio isso. $E$ ser solidária, inclusive, é você ser capaz de ser honesto com o outro. [...] Eu me sinto convocada, aqui na Marcha das Vadias, a estabelecer relações reais que têm seus conflitos, seus problemas e me sentir à vontade pra lidar com esses conflitos. Eu acho que é um espaço que admite com certa tranquilidade o conflito, as divergências, que não me chama pra essa unidade... (Regina, MdV de Fortaleza, 2017).

Segundo Rancière (1996), o dissenso é a condição da política, pois é o conflito que recusa o consenso como a imposição de uma ordem autoritária. Portanto, ao invés de prejudicar, o dissenso revitaliza, estimula e aprofunda a democracia. Para Regina, poder discordar e ser honesta com as companheiras tornava o ambiente da MdV menos "pesado" em relação a outros espaços que, segundo ela, giravam em torno de uma falsa sensação de harmonia, construída por uma ideia de "sororidade" e "união" que estava pautada em uma perspectiva essencialista de "mulher", ligada à genitália, e que dizia que todas deveriam se compreender e se amar, como se não existissem diferentes formas de "ser mulher".

Assim, diferente de outros grupos, as MdV brasileiras se construíram como espaços abertos às subjetividades e corpos plurais e, entendendo o dissenso como parte da política, viam as experiências de disputa como determinantes para o desenvolvimento e o fortalecimento de seus posicionamentos políticos.

Um exemplo de dissenso considerado determinante para o posicionamento da MdV de Fortaleza ocorreu em 2014, quando a convocatória para a Marcha foi feita com uma imagem do Translendário, um calendário com fotos de pessoas trans. Segundo llana, uma das organizadoras, a publicação on-line da imagem fez com que pessoas identificadas como feministas radicais passassem a denunciar a MdV de Fortaleza como um espaço que não era seguro para as mulheres.

[...] até que foi no contexto dessa discussão virtual [...] e aí teve um momento lá que tinha umas quinze RADFEMs [...] "protagonismo", não sei quê [...]. A gente nunca teve nenhuma questão, os meninos que participaram da Marcha, você viu, participavam muito tranquilamente como pessoas [...] que não estavam disputando protagonismo, porque a questão do protagonismo nunca foi uma questão pra nós. Justamente se trata, pra gente, de antagonismo a esses espaços. E aí, no contexto dessa discussão, [...] não sei o que deu, pego e digo: "moça, eu sou trans, eu tenho vagina, eu tenho ovário, tenho quatro filhos, mas sou trans, female to female". [...] E aí a discussão aumentou e nesse contexto eu pego e uso a expressão: "Não, [...] protagonismo não, o nosso feminismo é antagonismo, é transfeminismo antagonista". E aí a gente pegou e colocou esse tema na Marcha de 2014. Foi a primeira ocasiáo que teve, de fato, uma treta (llana, Mdv de Fortaleza, 2017).

O dissenso, mesmo que provocado nas redes sociais on-line, gerou um movimento na MdV de Fortaleza que passou a se apresentar como "transfeminista antagonista", isto é, um espaço que não está pautado pelo "protagonismo" das mulheres cis mas, ao contrário, como antagonista a toda a "ordem" cisheteronormativa, capitalista e racista que oprime diversos grupos de pessoas, especialmente as mulheres trans. Este posicionamento, embora não tenha provocado mudanças na configuração da MdV de Fortaleza, que já contava com a presença de pessoas trans na organização, fortaleceu ainda mais seu posicionamento interno.

Outras disputas relatadas por várias organizadoras das MdV brasileiras envolvem a presença de pessoas de partidos políticos. Embora não seja fechada às pessoas filiadas aos partidos, o debate envolvia, geralmente, a exposição de suas bandeiras nos atos de rua. A cada ano, quando o debate surgia, a decisão sobre poder ou não levar bandeiras partidárias na Marcha era definida pelas pessoas autodenominadas autônomas que, sendo maioria, justificavam o objetivo de afirmar e visibilizar o caráter autônomo, auto-organizado e horizontal da manifestação. Segundo Nathália, da MdV de Florianópolis, esta disputa acabava por gerar rachas e rompimentos dentro da organização, com pessoas ligadas aos partidos se afastando do grupo. Este posicionamento político, portanto, fez com que tanto as pessoas autônomas tivessem mais peso nas decisões da organização, por serem a maioria, quanto as decisões tomadas com o viés da autonomia, que acabaram determinando quem se somava e permanecia na organização das Marchas.

\section{Considerações finais}

As experiências relatadas pelas organizadoras de cinco Marchas das Vadias no Brasil nos permitiram refletir como e em que níveis os afetos e as emoções compõem o engajamento e a atuação política das MdV.

Desde como são afetadas ao "estar na rua", na manifestação, até a sua atuação na construção das marchas, pautada na horizontalidade e autonomia, as organizadoras passam por processos de formação política feminista que envolve, não só a compreensão de algumas opressões estruturais que incidem sobre os corpos feminilizados - mulheres cis e trans, hetero, bi ou lésbicas, brancas, negras, indígenas, entre outros marcadores - mas, também, o compartilhamento 
e contato com experiências múltiplas que possibilitam construir afetos como a empatia e a amizade. Assim, a dor, a indignação, o medo, o acolhimento, o pertencimento, o assombro e a esperança são afetos que, em espaços feministas, têm alto potencial político.

Como espaços de mobilização política, as Marchas das Vadias criam possibilidades múltiplas, seja em direção a uma politização em prol da luta, seja em direção a uma experiência de incômodo, questionamento e rechaço. As formas de expressar as múltiplas lutas, corporificadas no espaço público, afetam e provocam os sentidos tanto de quem participa das Marchas quanto das pessoas que as observam. Esse processo de ser afetada/o pelas Marchas pode tanto gerar emoções ligadas à união e à força, quanto provocar sentimentos de choque e, até mesmo, repulsa. Independente dos efeitos, os afetos provocam uma abertura, impõem às sujeitas e aos sujeitos - tanto de dentro quanto de fora - uma mobilização, um movimento. Os sujeitos deixam de ser quem eram; são provocados, de alguma maneira, a uma mudança, a um deslocamento que pode aumentar sua potência.

Assim, tanto na afetação mais imediata, que ocorre durante as Marchas, quanto no resgate desses afetos pela memória, trazido durante as entrevistas, o aumento da potência de ação das organizadoras se relacionou tanto à identificação com as violências sofridas de maneira sistemática contra corpos de mulheres cis, pessoas trans, travestis e prostitutas, mas, principalmente, na sensação de "estar junto", construir uma coletividade onde se pode experimentar lugares e de formas de expressão até então interditadas para seus corpos presos historicamente pelo sistema heterocispatriarcal.

Pensar os afetos e as emoções como parte da condição humana e, portanto, como inerentes às ações políticas, socialmente e culturalmente marcadas, significa ultrapassar análises baseadas numa ideia restrita da "razão", entendida como a identificação com a pauta, e perceber aquilo que afeta seus sentidos, provoca emoções, move as sujeitas e remodela seus corpos, em direção a uma transformação. As Marchas das Vadias fizeram emergir, na sociedade brasileira, novas formas de ser feministas, das quais outros movimentos já têm se apropriado, como se vê nas Marchas do 8M, por exemplo, e em tantas outras (Cara SNYDER et al., 2018). Essa apropriação não é somente de uma estética, mas de uma política que envolve os corpos, os sentidos, as emoções e afetos e sua potência.

\section{Referências}

AHMED, Sara. La política cultural de las emociones. Tradução de Cecília Olivares Mansuy. México, DF: Universidad Nacional Autónoma de México, 2015.

AHMED, Sara. Vivir una vida feminista. Tradução de María Enguix. Barcelona: Bellaterra, 2018.

BENTO, Berenice Alves de Melo. O que é transexualidade. São Paulo: Brasiliense, 2008.

GUZZO, Morgani. Corpos e campos plurais: os feminismos das Marchas das Vadias no Brasil. 2019. Tese (Doutorado) - Centro de Filosofia e Ciências Humanas, Programa de Pós-Graduação em Ciências Humanas, Universidade Federal de Santa Catarina, Florianópolis, 2019.

HEMMINGS, Clare. "Invoking affects. Cultural theory and the ontological turn". Cultural Studies, v. 19, n. 5, p. 548-567, set. 2005. Disponível em https://www.tandfonline.com/doi/abs/10.1080/09502380500 365473. Acesso em 12/08/2019.

JAQUET, Chantal. A unidade do corpo e da mente. Afetos, ações e paixões em Espinoza. Tradução de Marcos Ferreira de Paula e Luís César Guimarães Oliva. Belo Horizonte: Autêntica, 2011.

PEDRO, Joana Maria. "As mulheres e a separação das esferas". Diálogos, Maringá, v. 4, n. 1, p. 33 39, 2000. Disponível em http://periodicos.uem.br/ojs/index.php/Dialogos/article/view/37600. Acesso em 12/08/2019.

PEDRO, Joana Maria. "Narrativas Fundadoras do feminismo: poderes e conflitos (1970-1978)". Revista Brasileira de História, São Paulo, v. 26, n. 52, p. 249-272, dez. 2006. Disponível em http:// www.scielo.br/scielo.php?script=sci_arttext\&pid=S0102-0188200600020001 1. Acesso em 12/08/ 2019.

PEDRO, Joana Maria. "Os feminismos e os muros de 1968, no Cone Sul". Clio, Recife, v. 26, n. 1, p. 5982, jan./jun. 2008. Disponível em https://periodicos.ufpe.br/revistas/revistaclio/article/view/24194/ 19633. Acesso em 12/08/2019.

PEÑA, Julia Antivilo. Entre lo sagrado y lo profano se tejen rebeldías. Arte feminista nuestro americano. Bogotá: Ediciones desde Abajo, 2015.

RANCIÈRE, Jacques. A partilha do sensível: estética e política. Tradução de Mônica Costa Netto. São Paulo: EXO Experimental Org.; Ed. 34, 2005. 
RANCIÈRE, Jacques. O desentendimento: política e filosofia. Tradução de Ângela Leite Lopes. São Paulo: Ed. 34, 1996.

SEIGWORTH, Gregory J.; GREGG, Melissa. "An Inventory of Shimmers". In: GREGG, Melissa; SEIGWORTH, Gregory J. (Eds.). The affect theory reader. Durham \& London: Duke University Press, 2010. p. 1-25.

SNYDER, Cara K.; VEIGA, Ana Maria; WOLFF, Cristina Scheibe. "'América Latina Vai Ser Toda Feminista': Visualizing \& Realizing Transnational Feminisms in the Women's Worlds March for Rights". Ada: A Journal of Gender, New Media, and Technology, n. 14, 10.5399/uo/ada.2018.14.2, 2018. Disponível em https://adanewmedia.org/2018/1 1/issue14-snyderveigawolff/. Acesso em 12/08/2019.

VELÁSQUEZ, Susana. Violencias Cotidianas, Violencia de género: escuchar, aprender, ayudar. Buenos Aires: Paidos Iberica, 2003.

Morgani Guzzo (morganiguzzo@gmail.com) é doutora em Ciências Humanas pela Universidade Federal de Santa Catarina (2019), integrante do Instituto de Estudos em Gênero (IEG/ UFSC) e do Laboratório de Estudos de Gênero e História (LEGH/UFSC). Realiza pesquisas relacionadas aos temas gênero, movimentos sociais, feminismos e comunicação.

Cristina Scheibe Wolff (cristiwolff@gmail.com) é Professora Titular do Departamento de História da Universidade Federal de Santa Catarina (UFSC), doutora em História Social pela Universidade de São Paulo (USP) e integrante do Instituto de Estudos de Gênero (IEG/UFSC) e do Laboratório de Estudos de Gênero e História (LEGH/UFSC). Realiza pesquisas relacionadas aos temas gênero, feminismos e ditaduras no Cone Sul.

\section{COMO CITAR ESSE ARTIGO DE ACORDO COM AS NORMAS DA REVISTA}

GUZZO, Morgani; WOLFF, Cristina Scheibe. "Afetos no engajamento político das Marchas das Vadias no Brasil (2011-2017)". Revista Estudos Feministas, Florianópolis, v. 28, n. 2, e72429, 2020.

\section{CONTRIBUIÇÃO DE AUTORIA}

Morgani Guzzo: Concepção, coleta de dados e análise de dados, elaboração do manuscrito, redação, discussão de resultados.

Cristina Scheibe Wolff: Concepção, análise de dados, discussão de resultados, revisão do manuscrito.

\section{FINANCIAMENTO}

O presente trabalho foi realizado com apoio da Coordenação de Aperfeiçoamento de Pessoal de Nível Superior - Brasil (CAPES) - Código de Financiamento 001.

\section{CONSENTIMENTO DE USO DE IMAGEM}

Não se aplica.

\section{APROVAÇÃO DE COMITÊ DE ÉTICA EM PESQUISA}

Não se aplica.

\section{CONFLITO DE INTERESSES}

Não se aplica.

\section{LICENÇA DE USO}

Este artigo está licenciado sob a Licença Creative Commons CC-BY International. Com essa licença você pode compartilhar, adaptar, criar para qualquer fim, desde que atribua a autoria da obra.

\section{HISTÓRICO}

